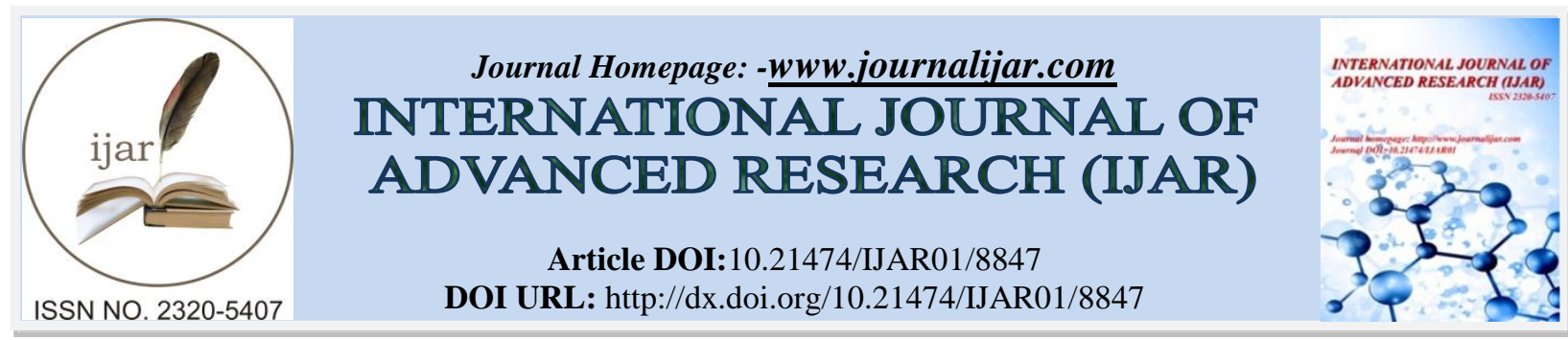

RESEARCH ARTICLE

\title{
SENSORY IMPROVEMENT AND REDUCTION OF NERVE THICKENING IN A LEPROSY PATIENT TREATED WITH ULTRASOUND GUIDED PERINEURAL INJECTION OF AUTOLOGOUS PLATELET- RICH PLASMA: A CASE REPORT AND REVIEW OF LITERATURE.
}

Dr. Raktim Swarnakar ${ }^{1}$ and Dr. Hafis Rahman ${ }^{2}$.

1. MBBS, Post Graduate Resident, Department of Physical Medicine and Rehabilitation (PM\&R), All India Institute of Medical Sciences (AIIMS), New Delhi, India 110029.

2. MBBS, MD, Senior Resident, Department of Physical Medicine and Rehabilitation (PM\&R), All India Institute of Medical Sciences (AIIMS), New Delhi, India 110029.

\section{Manuscript Info}

\section{Manuscript History}

Received: 08 February 2019

Final Accepted: 10 March 2019

Published: April 2019

Key words:-

Leprosy, Neuropathy, Platelet-rich plasma.

\section{Abstract}

Background: Leprosy is caused by Mycobacterium leprae which has a certain predilection for peripheral nerves. It causes peripheral neuropathy and in the long run, it causes deformity of hands and feet. Platelet-rich plasma (PRP) which contains a variety of growth factors can stimulate neural regeneration.

Materials \& Methodology: A case report and review of literature (PubMed, Embase, Google Scholars, and other electronic search engines) were done. In a 45-year-old male leprosy patient, ultrasoundguided perineural autologous PRP $(1 \mathrm{ml})$ injection was given at the right ulnar nerve under all aseptic precautions.

Results: Right ulnar nerve showed sensory improvement especially in ulnar distribution. In ultrasound, right ulnar nerve showed mild reduction in mean cross-sectional area whereas the left ulnar nerve showed no changes. Interventions which were ethically supported by existing literature and evidences were followed and reviewed.

Conclusion: To the best of our knowledge, this is the first case report where ultrasound-guided intervention was done, a long term follow-up for 4 weeks was followed and nerve thickness comparison was done. Here, PRP showed its promising role to reduce the nerve thickness and to improve the sensory function in leprosy.

Copy Right, IJAR, 2019,. All rights reserved.

\section{Introduction:-}

Leprosy (Hansen's disease) is a chronic granulomatous disease, caused by Mycobacterium leprae, which affects the peripheral nerves leading to sensory loss and deformity. Peripheral nerve regeneration can be stimulated by various growth factors and platelet-rich plasma (PRP) contains those similar growth factors. Here we are reporting a case of leprosy in which ultrasound guided perineural autologous PRP injection was given and outcome measures like sensory improvement by assessing visual analogue scale (VAS) and nerve thickness assessing by mean cross-section area (CSA) measurement by ultrasound (USG) were taken. 


\section{Case Report:}

Setting: Rehabilitation setting in an urban tertiary care center.

Case: A 45 year old male, histologically confirmed case of leprosy, with bilateral thickened ulnar nerve with grade 2 deformity in hands (Right > left), came for rehabilitation care. Patient was on multidrug therapy (MDT).

Intervention: Ultrasound guided single perineural autologous PRP $(1 \mathrm{ml})$ injection was given at the right ulnar nerve under all aseptic precautions. Left ulnar nerve was served as a control. Routine rehabilitation care and MDT were continued. We chose to inject PRP in right ulnar nerve as it had more severe involvement than left ulnar nerve and it will help to detect mild changes after injections. There were no any adverse events or complications during and after injection.

Outcome measures: VAS (0, no sensation to 100, normal sensation) for sensory assessment and mean CSA of ulnar nerve measured by USG for nerve thickening.were taken at base baseline and 4 week after PRP injection.

\section{Results:}

Right ulnar nerve showed sensory improvement especially in ulnar distribution from 0 (pre-intervention) to 30 (after 4 week of post-intervention) in VAS. Left ulnar nerve showed no changes (20 in VAS). In USG measurement of mean CSA, right ulnar nerve (Figure 1 and Figure 2) showed mild reduction whereas left ulnar nerve showed no changes.

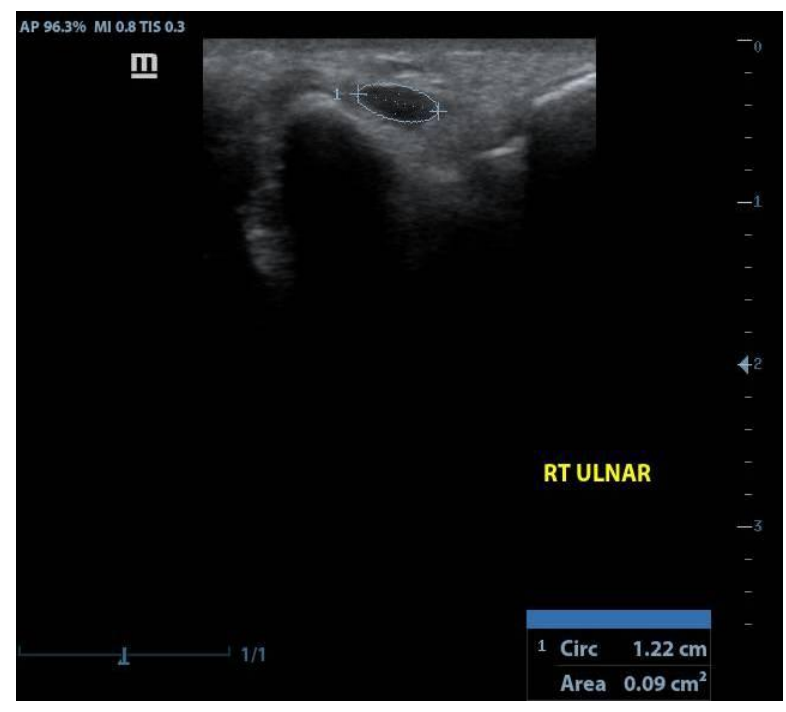

Figure 1:-Right Ulnar nerve area measurement before PRP injection

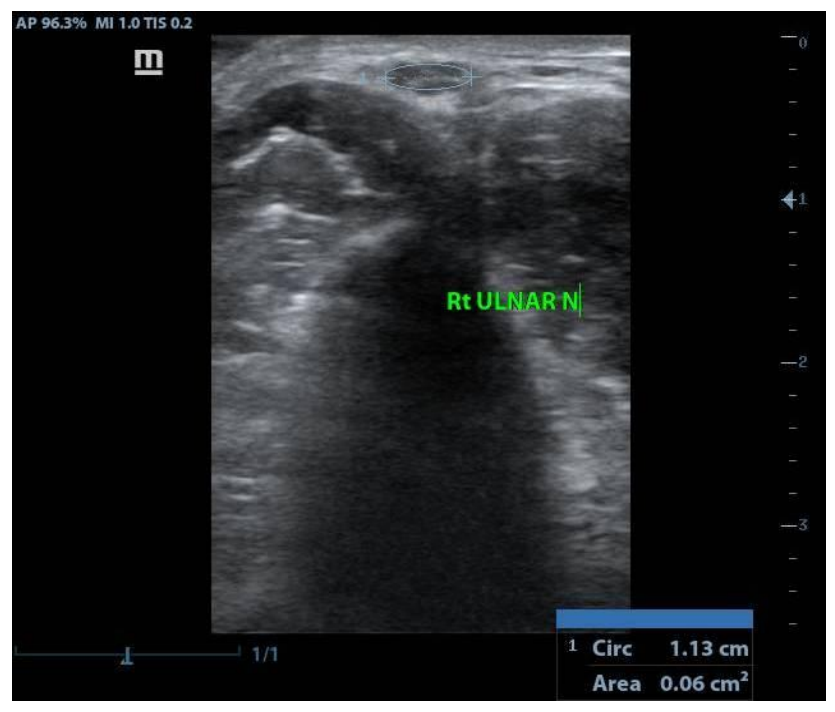

Figure 2:-Right Ulnar nerve area measurement after PRP injection

\section{Method of Literature Review:}

For review of literature on PRP effects in Leprosy affected nerves we used search engines like PubMed, Embase, Google Scholars and other electronic search engines to get important relevant evidences. Studies that are found to be relevant in PRP in neural regeneration and more importantly in Leprosy patient, have been included for review.

\section{Discussion:-}

Though relatively a few human trials have showed PRP therapy, there is increasing evidence from in vitro and animal studies. PRP has been used to study the effect of stimulating nerve regeneration of the rat facial nerve, ${ }^{1}$ rat sciatic nerve, ${ }^{2,3}$ rabbit sciatic nerve, These studies showed positive results regarding nerve recovery in functional perspectives, regeneration of axons, ${ }^{1,2}$ g-ratio (an index of optimal axonal myelination), thickness of the myelin sheath, nerve conduction velocity, ${ }^{4}$ revascularization and reinnervation, ${ }^{5}$ and axon diameter ${ }^{6}$. 
On the basis of the currently available evidence, platelet-rich plasma (PRP), which contains many growth factors that showed positive impact on neural cell survival, might have the potential to promote peripheral nerve regeneration ${ }^{7}$.

There is one double-blind, randomized, control clinical trial on PRP injections in 60 patients with leprosy peripheral neuropathy, here it showed PRP injection could promote improvement of peripheral neuropathy sensibility. ${ }^{8}$

Here in this case study we used ultrasound guided perineural injection to accurately localise the concerned nerve. We also measured the thickness of concerned nerve to find out any changes following PRP injection. To the best of our knowledge, in literature, there is no study observing changes in nerve thickness and changes in nerve conduction studies in leprosy peripheral neuropathy following PRP injections. In our study, nerve thickness measurements were taken to see the changes following perineural PRP injection. Leprosy causes neural inflammation and after injecting PRP thickness was reduced, this is due to that fact that PRP has an anti-inflammatory property as well.

\section{Uniqueness of this case report \& review:}

Furthermore, this case study is unique in the sense that, for the first time perineural PRP injection in leprosy peripheral neuropathy is attempted where,

1. We used ultrasound guided intervention,

2. A long term follow-up for 4 week was done,

3. Nerve thickness comparison was done,

4. We did not inject Platelet poor plasma as control arm; rather we used routine rehabilitative care as control.

5. Interventions which were ethically supported by existing literature and evidences were followed and reviewed.

\section{Conclusion:-}

This case showed that PRP may reduce the nerve thickness and may improve the sensory function in leprosy. It is seen that PRP could serve as a promising agent in terms of peripheral nerve regeneration research. But further research on electrodiagnostic studies and a more long term follow-up are needed in such cases.

\section{References:-}

1. Farrag TY, Lehar M, Verhaegen $P$ et al. Effect of platelet rich plasma and fibrin sealant on facial nerve regeneration in a rat model. Laryngoscope 2007; 117(1):157-165.

2. Elgazzar RF, Mutabagani MA, Abdelaal SE et al. Platelet rich plasma may enhance peripheral nerve regeneration after cyanoacrylate reanastomosis: a controlled blind study on rats. Int J Oral Maxillofac Surg 2008; 37(8): 748-755.

3. Sariguney Y, Yavuzer R, Elmas $\mathrm{C}$ et al. Effect of platelet-rich plasma on peripheral nerve regeneration. J Reconstr Microsurg 2008; 24(3): 159-167.

4. Ye F, Li H, Qiao G et al. Platelet-rich plasma gel in combination with Schwann cells for repair of sciatic nerve injury. Neural Regen Res 2012; 7(29): 2286-2292.

5. Xie X, Zhao S, Wu H et al. Platelet-rich plasma enhances autograft revascularization and reinnervation in a dog model of anterior cruciate ligament reconstruction. J Surg Res 2013; 183(1): 214-222.

6. Zhao T, Yan W, Xu K et al. Combined treatment with platelet-rich plasma and brain derived neurotrophic factoroverexpressing bone marrow stromal cells supports axonal remyelination in a rat spinal cord hemi-section model. Cytotherapy 2013; 15(7): 792-804.

7. Dagum AB. Peripheral nerve regeneration, repair, and grafting. J Hand Ther 1998; 11(2): 111-117.

8. Anjayani S, Wirohadidjojo YW, Adam AM et al. Sensory improvement of leprosy peripheral neuropathy in patients treated with perineural injection of plateletrich plasma. Int J Dermatol 2014; 53(1): 109-113. 